\title{
A EPISTEMOLOGIA DIALÉTICA NA ATIVIDADE PEDAGÓGICA: REALIDADE E POSSIBILIDADE NA FORMAÇÃO DO PROFESSOR DA INFÂNCIA
}

\author{
LA EPISTEMOLOGÍA DIALÉCTICA EN LA ACTIVIDAD PEDAGÓGICA: \\ REALIDAD Y POSIBILIDAD EN LA FORMACIÓN DEL PROFESOR DE LA \\ INFANCIA
}

\section{THE DIALECTICAL EPISTEMOLOGY IN PEDAGOGICAL ACTIVITY: REALITY AND POSSIBILITY IN TEACHER EDUCATION FROM CHILDHOOD}

\author{
Marta Silene Ferreira BARROS ${ }^{1}$ \\ Dayanne VICENTINI ${ }^{2}$
}

\begin{abstract}
RESUMO: O presente estudo tem como objetivo central, compreender a importância do conhecimento científico na práxis pedagógica do professor da infância. A pesquisa se justifica devido ao fato de grande parte dos educadores infantis receberem uma formação precária, refletindo em práticas pautadas no senso comum, em detrimento do conhecimento científico. Isso vem ocasionando uma fragilidade em sua práxis pedagógica, que acaba por interferir na qualidade da aprendizagem e do desenvolvimento da criança. A metodologia elegida para a realização do estudo está pautada na pesquisa bibliográfica, a qual subsidiou-se nos pressupostos da epistemologia dialética. Os resultados revelaram que as práticas espontâneas estão presentes na atividade pedagógica do professor de Educação Infantil e não proporcionam o conhecimento científico por parte do educador. Diante do exposto, avalia-se como possibilidade, a superação dessas práticas por meio da apropriação do conhecimento científico e a defesa do ensino intencional baseado em estudos e pesquisas para a realização de uma práxis de qualidade junto à criança pequena.
\end{abstract}

PALAVRAS-CHAVE: Educação. Epistemologia dialética. Atividade pedagógica. Formação do Professor.

RESUMEN: El presente estudio tiene como objetivo central, comprender la importancia del conocimiento científico en la praxis pedagógica del profesor de la infancia. La investigación se justifica debido al hecho de que gran parte de los educadores infantiles reciben una formación precaria, reflejando en prácticas pautadas en el sentido común, en detrimento del conocimiento científico. Esto viene ocasionando una fragilidad en su praxis

\footnotetext{
${ }^{1}$ Universidade Estadual de Londrina (UEL), Londrina - PR - Brasil. Docente da Universidade Estadual de Londrina (UEL) do Departamento de Educação e da Pós-Graduação em Educação. Pós-Doutorado em Educação pela Universidade Estadual Paulista (UNESP). E-mail: mbarros_22@hotmail.com

${ }^{2}$ Universidade Estadual de Londrina (UEL), Londrina - PR -Brasil. Professora de Educação Infantil e dos Anos Iniciais do Ensino Fundamental. Graduada em Pedagogia pela Universidade Estadual de Londrina (UEL). Mestre em Educação pela Universidade Estadual de Londrina (UEL). E-mail: dayannevicentini@hotmail.com
}

RIAEE - Revista Ibero-Americana de Estudos em Educação, Araraquara, v. esp, n. 3, p. 1952-1963, dez., 2018. E-ISSN: $1982-5587$. 
pedagógica, que acaba por interferir en la calidad del aprendizaje y del desarrollo del niño. La metodología elegida para la realización del estudio está pautada en la investigación bibliográfica, la cual se subsidió en los presupuestos de la epistemología dialéctica. Los resultados revelaron que las prácticas espontáneas están presentes en la actividad pedagógica del profesor de Educación Infantil y no proporcionan el conocimiento científico por parte del educador. Ante la expuesta, se evalúa como posibilidad, la superación de esas prácticas por medio de la apropiación del conocimiento científico y la defensa de la enseñanza intencional basada en estudios e investigaciones para la realización de una praxis de calidad junto al niño pequeño.

PALABRAS CLAVE: Educación. Epistemología dialéctica. Actividad pedagógica. Formación del profesor.

ABSTRACT: The present study has as it is central objective, understand the importance of scientific knowledge in pedagogical praxis of professor of childhood. The research is justified due to the fact that a large part of the infant teachers receiving a training precarious, reflecting on practices based on common sense, to the detriment of scientific knowledge. This is causing a weakness in their pedagogical praxis, which interfere with the quality of learning and the development of the child. The methodology chosen for the study is based on bibliographical research, that is, if the assumptions of dialectical epistemology. The results showed that spontaneous practices are present in the pedagogical activity of professor of Early Childhood Education and do not provide the scientific knowledge on the part of the educator. Given the above, it is evaluated as a possibility, the overcoming of these practices by means of appropriation of scientific knowledge and the defense of the intentional teaching based on studies and research for the realization of a praxis of quality next to the small child.

KEYWORDS: Education. Dialectical epistemoloy. Pedagogical activity. Teacher training.

\section{Introdução}

A Educação formal, como sendo uma esfera ampla e complexa da sociedade, tornou-se alvo de inúmeros debates entre filósofos, sociólogos, psicólogos e pedagogos durante as últimas décadas. Sabe-se que ao longo da história, que teorias foram elaboradas com o intuito de contribuir para a formação do ser humano por meio do ato educacional. A função social da escola e a relação aluno/criança e professor, na maioria das vezes constituíram-se de fundamental importância nas discussões acerca dos mais diversos modelos pedagógicos.

Ao buscarmos nas fontes da Epistemologia Materialista-Dialética- as bases filosóficas, na Teoria Histórico-Cultural - as bases psicológicas e na Perspectiva HistóricoCrítica, as bases pedagógicas para o ensino, encontramos a escola como o lócus 
privilegiado de socialização do conhecimento elaborado e o professor como um ator fundamental no cenário do ensino e aprendizagem da criança, ressaltando que nessa base o professor é considerado mediador do processo de aprendizagem e desenvolvimento. De acordo com Saviani (2013) a escola possui como função primeira, a disseminação do conhecimento elaborado, isto é, do conhecimento científico. Portanto, a formação do professor, pautada no Materialismo Histórico-Dialético - o qual pode ser compreendido como epistemologia, na medida em que apresenta os subsídios essenciais para a compreensão do contexto social amplo, possibilita a prática de um trabalho pedagógico organizado e intencional, e, consequentemente, a socialização da cultura elaborada para as crianças. Em contrapartida, a formação continuada destinada aos professores da escola da infância no Brasil, pautam suas propostas de estudos em cursos aligeirados, "vazios" de fundamentos científicos, os quais consideramos imprescindíveis para um trabalho de qualidade junto às crianças.

Assim, o ensejo dessa pesquisa, justifica-se devido ao fato de que muitos professores trabalham ancorados em práticas espontâneas, isto é, no conhecimento do senso comum, em detrimento do conhecimento científico, o que acarreta fragilidade em sua prática pedagógica, que interfere na qualidade da aprendizagem e desenvolvimento da criança. A partir disso, a problemática posta em questão é conhecer de que modo o conhecimento científico contribui na práxis pedagógica do professor da infância?

Neste sentido, para atender ao problema de estudo, o objetivo principal da pesquisa é apresentar a importância do conhecimento científico na práxis do professor da infância com a finalidade de valorizar a formação como subsídio essencial para o desenvolvimento do professor.

\section{A formação de professores no Brasil: os efeitos sobre o trabalho do profissional na escola da infãncia}

Atualmente, a formação continuada, no Brasil, apresenta inúmeros enfrentamentos. De acordo com Chaves (2014, p. 121), são poucos os recursos destinados para a formação continuada do professor, além disso, as ofertas de formação limitam-se a uma proposta de estudos "frágil e desconexa." Com o intuito de aligeirar o tempo de capacitação, impulsiona-se a oferta de cursos cujos objetivos não são consoantes com reflexões e pesquisas que indiquem ou anunciem a compreensão de uma prática pedagógica em favor de uma educação que seja capaz de propiciar a aprendizagem e desenvolvimento das

RIAEE - Revista Ibero-Americana de Estudos em Educação, Araraquara, v. esp, n. 3, p. 1952-1963, dez., 2018. E-ISSN: 1982-5587. 
crianças para além de sua realidade imediata.

A partir disso, Chaves (2014), faz uma crítica aos cursos de formação:

Se, de um lado, há uma significativa oferta de cursos para a formação dos professores disponibilizados por editoreas, instituições de ensino superior, associações e empresas de consultoria pedagógica, coloca-se, por outro, a necessidade de refletir sobre essas ofertas quantitativas e suas consequências para a prática educativa que se efetiva junto às crianças (CHAVES, 2014, p. 121).

Sob esse ponto de vista, cumpre destacar que não é a quantidade de cursos realizados que determina a qualidade da formação dos professores, mas o conteúdo que a fundamenta, de forma concreta e coerente. Propostas de estudos desconexos podem fragilizar a prática pedagógica do professor da infância. De acordo com Chaves (2014), o aligeiramento e a fragmentação estão muito presentes nos cursos de graduação e pósgraduação de diferentes áreas, assim como, nos de capacitação continuada.

Esse fato acentua, ainda mais, a alienação em nome da formação dos profissionais da educação. A superficialidade encontrada na formação continuada é uma característica própria do capitalismo na sociedade atual brasileira, pois, ao fragilizar o conhecimento do professor nesses cursos, o Estado almeja práticas que estejam em consonância com a legitimação da ordem social estabelecida, considerada natural, inalterável. Assim, os indivíduos devem ser:

[...] induzidos a uma aceitação ativa (ou mais ou menos resignada) dos princípios reprodutivos orientadores dominantes na própria sociedade, adequados a sua posição na ordem social e de acordo com as tarefas reprodutivas que lhes foram atribuídas. (MÉSZÁROS, 2007).

Nesse contexto, o Estado sob influência do sistema capitalista, ao oferecer cursos rápidos, frágeis e fragmentados aos profissionais da educação, está "camuflando" o verdadeiro sentido da formação continuada: o estudo teórico e a reavaliação das práticas educativas efetuadas nas escolas. Em contrapartida, com a secundarização do conhecimento, essas práticas ficam cada vez mais difíceis de serem realizadas. Raupp e Arce (2012) enfatizam que esse movimento acontece, principalmente, na Educação Infantil, pois está havendo um "recuo" da teoria em pesquisas e um esvaziamento do conteúdo na escola.

Em vista disso, Chaves (2014) sinaliza que o governo vem intensificando a oferta de capacitação de professores que atuam no Ensino Fundamental e Médio, por meio de 
cursos e projetos especiais oferecidos por Estados e Municípios. Em contrapardida, a Educação Infantil não recebe prioridade nesse quesito, o que confirma, ainda mais, a secundarização do conhecimento do professor desse nível de ensino. Desse modo, por um lado:

[...] há intensificação de discursos em favor da criança pequena, enquanto, por outro lado, são negadas aos seus professores condições efetivas de aprimoramento que os instrumentalizem para práticas educativas mais consequentes em favor de uma Educação Infantil humanizadora (CHAVES,2014, p.124).

Esse cenário piora quando se trata de profissionais da Educação Infantil, que trabalham com crianças menores de três anos, pois há uma desvinculação do ensino nesse nível educacional. Ouvimos que "os professores que atuam com crianças menores não necessitam tanto de curso, porque para os pequenos é mais é brincar” (CHAVES,2014, p. 125 , grifo da autora).

Sob as bases da Epistemologia Materialista Dialética, a Pedagogia HistóricoCrítica, considera que a escola da infância configura-se como uma instituição de dimensão pedagógica, e, assim, como espaço de trabalho do professor, portanto o ensino é o eixo do desenvolvimento das crianças pequenas. É nesse pensamento que o presente estudo se configura e avalia que que o papel principal da escola - não importa o nível de ensino, é a socialização do saber sistematizado, e não de qualquer saber, assim, os estabelecimentos de ensino são espaços, por exelência, para a disseminação do conhecimento elaborado, isto é, do conhecimento científico, e não o espontâneo (senso comum), o saber sistematizado e não fragmentado, a cultura erudita e não a popular. Nesse sentido, segundo Oliveira (1987, p. 92), a escola, como um dos organismos da sociedade civil, "é o local por exelência para o desenvolvimento do processo de transmissão-assimilação do conhecimento elaborado." Assim, podemos enfatizar que os estabelecimentos educacionais instrumentalizam os indivíduos para atuarem no meio social ao qual pertencem.

Saviani (2013) salienta que a escola, nesse sentido, tem a ver com o problema da ciência, pois, com efeito, esta configura-se como saber sistematizado, metódico, não o conhecimento produzido por “palpites" ou "achismos", que não justifica a existência das instituições escolares.

A sabedoria baseada na experiência de vida dispensa e até mesmo 
desdenha a experiência escolar, o que, inclusive, chegou a cristalizar-se em ditos populares como: " mais vale a prática do que a gramática" e "as crianças aprendem apesar da escola". É a exigência de apropriação do conhecimento sistematizado por parte das novas gerações que torna necessária a existência da escola. (SAVIANI, 2013, p. 14).

A escola existe para que o saber científico, elaborado historicamente pela humanidade, seja socializado, pois este conhecimento, segundo a Teoria HistóricoCultural, possibilita a transformação das funções psíquicas elementares (caráter biológico) em funções psíquicas superiores (linguagem, atenção, memória, sensação, percepção, entre outros), que são, culturalmente, adquiridas pelo homem. Assim, a apropriação do saber científico, isto é, das formas mais elaboradas de conhecimento criadas pelo homem ao longo da história, potencializa seu desenvolvimento como ser humano social.

Para Mello e Farias (2010), a escola pode realizar uma educação que promova o máximo desenvolvimento humano nas crianças, sem abreviar sua infância e respeitando as formas de relação da criança pequena com o mundo da cultura que a cerca, pois não podemos limitar seu acesso às formas mais elaboradas de cultura, mas abrir possibilidades de contato, para que a escola seja um espaço de humanização.

\section{O conhecimento científico na atividade pedagógica do professor}

A Teoria Histórico-Cultural percebe o ser humano como produto da história, da sociedade e da cultura, e seu desenvolvimento como resultado, e não condição, do processo de aprendizagem, pois as experiências vividas impulsionam o desenvolvimento. Assim, sem aprendizagem (sem experiências vividas), não há desenvolvimento humano. É nesse sentido que a educação das crianças deve assumir um caráter propulsor do desenvolvimento infantil.

Raupp e Arce (2012) apontam que, na educação escolar das pequenas crianças brasileiras, existe uma tendência de se desvincular esse nível de educação do ensino e aprendizagem, por considerar a Educação Infantil apenas como instância cuidadora de crianças com caráter assistencialista. Essa tendência retira o ensino como elemento que possibilita o desenvolvimento das crianças pequenas, ocasionando a desintelectualização docente. Nesse contexto, o professor da infância é visto apenas como um "cuidador de crianças", que não carece de conhecimentos científicos para realizar seu trabalho educativo e, desse modo, é secundarizado. Como consequência, a Educação Infantil acaba por realizar um "recuo da teoria", esvaziando o conteúdo na escola e secundarizando o 
conhecimento na formação de professores.

A partir dos fundamentos epistemológicos do Materialismo Histórico-Dialético, consideramos o ensino como eixo do trabalho com crianças de 0 a 3 anos, como ocorre em qualquer outro nível de educação, assim, é preciso superar o pragmatistmo e o espontaneísmo que predominam na educação de crianças pequenas. As práticas espontaneístas estão intimamente relacionadas a ideias construtivistas, que consideram que a aprendizagem depende das competências cognitivas e da interação em atividades de seu interesse ( MARTINS; MARSIGLIA, 2015).

É mister avaliar que um ensino fundamentado em práticas espontaneístas concebe o professor como sujeito coadjuvante no processo de ensino e aprendizagem, pois entende que a criança aprende a partir de seus próprios interesses, que formam sua inteligência. Dessa forma, nesse contexto, qual seria, então, a função do professor? Seu papel estaria vinculado a considerar, primordialmente, o que a criança já sabe, acompanhando seu processo de desenvolvimento. O espontaneísmo, nessa perspectiva encerra as possibilidades de humanização da criança por meio do ensino, pois: Para que ensinar a criança, se é ela mesma quem produz seu próprio conhecimento?

A Teoria Histórico-Cultural, pelo contrário, defende a humanização da criança por meio do ensino, e entende o professor como o adulto que socializa com as crianças os resultados do desenvolvimento histórico, isto é, que apresenta os traços da atividade humana objetivada nos objetos da cultura (SILVA, 2012).

A criança pequena tem direito ao acesso ao há de mais de avançado em termos de elaboração humana: o saber sistematizado e fundamentado cientificamente, o que exige do professor um conhecimento profundo dos conteúdos que irá trabalhar em sua prática pedagógica. Todavia, não estamos tratando de qualquer conhecimento, conforme dito anteriormente, mas do conhecimento científico.

Se a escola é o espaço que trabalha com a cultura erudita, cabe ao professor buscar formas mais elaboradas de conhecimento para potencializar um ensino que promova o pleno desenvolvimento das crianças pequenas. Segundo Raupp e Arce (2012, p. 54), o ponto de partida do professor deve ser uma perspectiva onto-metodológica que pressupõe "uma realidade dada, independente da reflexão, que pode ser captada pelo agir humano, ação humana que coloca finalidades, ou seja, guiada por um objetivo que se procura atingir."

A prática, será mais coerente, consistente, qualitativa e desenvolvida, quanto mais

RIAEE - Revista Ibero-Americana de Estudos em Educação, Araraquara, v. esp, n. 3, p. 1952-1963, dez., 2018. E-ISSN: 1982-5587. 
coerente, consistente e qualitativa for a teoria que a embasa (SAVIANI, 2013). A intencionalidade do professor, isto é, o planejamento de sua prática de ensino, irá contribuir para que haja um trabalho de qualidade em relação ao desenvolvimento social da criança, com vistas a uma práxis revolucionária. Vázquéz (1968) assinala que a práxis revolucionária pode ser entendida como a coincidência da transformação das circunstâncias, ou do próprio homem, a partir da atividade humana. Para o autor, o homem não é somente produto das circunstâncias do meio em que vive, mas também sofre a influência decisiva da educação, que lhe possibilia sair do reino das "sombras" rumo ao reino da "razão". Nesse sentido, educar é uma possibilidade de transformar a humanidade.

Assim, enfatizamos: o professor também precisa ser educado, pois sua tarefa, cujo objetivo primeiro é transformar a humanidade, entretanto, muitas vezes, a criança "fica nas mãos de professores que, por sua vez, não se transformam a si mesmos, e cuja missão é transformar os demais" (VÁZQUEZ, 1968, p. 159). Educar-se requer munir-se dos resultados das produções humanas, ou seja, do conhecimento elaborado historicamente: o conhecimento científico.

Trabalhar por uma práxis revolucionária significa ensinar para que aconteçam revoluções no desenvolvimento infantil, para que cada estágio do desenvolvimento da criança possa se transformar em uma nova atividade-guia que a oriente no desenvolvimento de outros processos psíquicos. Segundo Arce (2004, p. 18), na perspectiva de Vygotsky, o desenvolvimento infantil é um processo dialético, pois "a passagem de uma fase a outra é marcada não pela simples evolução [...] mas por uma revolução que implicaria mudanças qualitativas na vida da criança.” O professor, nesse sentido, como mediador e responsável pelo processo de ensino e aprendizagem da criança, deve ser capaz de materializar suas ações a partir da teoria, apropriando-se de conceitos específicos relativos ao desenvolvimento da faixa etária em que trabalha. Entretanto, o que muito se tem visto, na prática educativa dos centros de Educação Infantil, é um trabalho ancorado em concepções advindas do senso comum. Esses improvisos, relacionam-se a um processo que:

[...] serve para resolver as demandas imediatas do cotidiano, ou seja, não tem cunho científico com o objetivo de investigar, desvelar as crenças cotidianas próprias da experiência imediata (RAUPP; ARCE, 2012, p. 66).

Esse conhecimento advindo da prática não "é suficiente para dar conta da 
complexidade do ato educacional, do ensino-aprendizagem e da formação" (TORRIGLIA, 2004, p. 265). A atividade de conhecer é aspecto crucial para formar professores que não se prendam ao campo imediato, pois, para que se possa comprender a experiência, é imprescindível considerar o caráter estrutural dos objetos e do mundo. Esse conjunto de eventos, no campo da empiria, por mais rica que esta seja, pressupõe um mundo ocluso para transformações e para a intervenção da ação do homem.

O modelo de ensino que defendemos ancora-se em uma visão sócio-histórica do desenvolvimento, que privilegia as relações sociais como mediação "fundamental na promoção de mudanças significativas nas capacidades das crianças de sentir, agir e pensar o mundo e a si mesmas" (OLIVEIRA et al, 2006, p. 565). Para Raupp e Arce (2012), é tarefa do professor saber como acontece a aprendizagem e o desenvolvimento da criança, ou seja, saber como ela se apropria dos conhecimentos e como ela explora o mundo circundante.

Para que haja uma práxis revolucionária no desenvolvimento infantil, é preciso que o professor vá além do cotidiano em si, ou seja, que busque o conhecimento científico como subsídio para um trabalho pedagógico que objetive o desenvolvimento dos processos psíquicos da criança, de modo a humanizá-la, torná-la um ser social dotado de qualidades tipicamente humanas. Nesse sentido, para Raupp e Arce (2012), os professores de Educação Infantil, para exercerem sua função de forma qualitativa, podem buscar uma formação teórica sólida, capaz de oferecer bases filosóficas, psícológicas e pedagógicas que permitam a compreensão dos processos de aprendizagem e desenvolvimento da criança .

O professor, ao se apropriar dos conhecimentos que envolvem os processos educativos, possibilita uma conexão entre o ponto de partida e o ponto de chegada de seu trabalho pedagógico, sem a qual "não é possível agir para transformar a possibilidade em realidade" (RAUPP; ARCE, 2012, p. 85). Oliveira (1987) destaca que a prática social global possui estreita relação com o ponto de partida e o ponto de chegada da prática educativa, pois considera que a vida cotidiana é o ponto de partida e de chegada de todas as atividades e conhecimentos do homem, desde suas mais simples criações até as mais elaboradas (ciência, arte).

As finalidades dessas formas, tanto as mais simples quanto as mais elaboradas, se especificam até chegarem a uma autonomia relativa frente à cotidianidade. Seus efeitos, voltam-se para a cotidianidade, de modo a influenciá-la. O desenvolvimento do cotidiano, 
enriquecido com essa influência, faz com que surjam novas exigências e ramificações do conhecimento humano e, por consequência, novas atividades correspondentes. Assim, ao almejar que o indivíduo se transforme em um agente de sua prática social, é preciso que ele seja capaz de dominar, da melhor forma possível, o conhecimento elaborado, existente na sociedade, inclusive a própria maneira de produzir esses saberes, que se torne o adulto experiente preconizado pela Teoria Histórico Cultural. Assim, cabe ao professor considerar as experiências vividas por seus educandos (ponto de partida), para que, ao internalizarem o novo conhecimento - o científico, esses indivíduos transformem sua maneira de pensar e passem a agir, conscientemente, em sua prática social (ponto de chegada) (OLIVEIRA, 1987). Esse processo, vincua-se a um movimento dialético.

Nesse contexto, de acordo com Mello (2007a, p. 12), o professor é o intelectual que "deve intencionalmente projetar e criar na escola as situações de vida e educação que possibilitem a internalização por cada criança das máximas qualidades humanas existentes na sociedade." Para organizar, intencionalmente, o trabalho educativo, é necessário que o professor ancore essas intenções em concepções/teorias que as fundamentem e orientem, visando à sua concretização em forma de ações (práticas). Apenas a apropriação efetiva de uma teoria permite aos professores a liberdade e as condições para analisar e refletir sobre os problemas da prática educativa, de modo a compreendê-los em sua complexidade, para poder projetar ações que sejam adequadas para enfrentá-los (MELLO, 2007b).

\section{Considerações finais}

Diante do exposto, consideramos que os cursos de formação, cujas propostas apresentam-se de forma aligeirada, empobrece a formação do professor, implicando de maneira precária atividade pedagógica na escola da infância. Sendo a escola como o espaço de excelência para a disseminação do conhecimento historicamente e culturalmente elaborado, defendemos que o professor como mediador no processo de ensino e aprendizagem, pode munir-se dos conhecimentos da ciência, uma vez que a Epistemologia Dialética, visa apreender estes conhecimentos vinculados à prática social por meio de seus movimentos e contradições. Dessa forma, concluímos, a partir desse estudo que a prática ancorada pelo senso comum, não garante o pleno desenvolvimento humano na criança.

As propostas dos cursos de formação, não podem prescindir de uma concepção de educação, pois esta é a que norteia e condiciona todo o trabalho do professor. Por esse 
motivo, é imperioso pensar em formações que contribuam significativamente com a práxis do professor, haja visto que propostas de estudos desconexos podem fragilizar a prática pedagógica, contribuindo para que o profissional da escola da infância trabalhe com a teia formada pelos seus conhecimentos, opiniões, impressões, crendices e superstições acumulados no decurso da vida, que de forma mais ou menos espontânea, acabam por orientar suas decisões e atividades práticas. (KLEIN, s/a).

Ao afirmarmos que a escola existe para a socialização do saber científico, é válido que o professor receba uma formação consistente, fundamentada em conhecimentos da cultura elaborada, de modo que sua atividade de ensino seja planejada e orientada por uma teoria que lhe ofereça os subsídios necessários para que o seu trabalho e, potencialize o desenvolvimento da criança como um ser humano histórico e social.

Sendo assim, a Teoria Histórico-Cultural é a abordagem que avaliamos mais coerente que contribuir com o trabalho do professor no contexto da Educação Infantil, pois ao conceber o homem como produto e produtor de história, contribui na formação científica do professor, posto que considera o conhecimento culturalmente elaborado como fonte do desenvolvimento social do homem. Conforme visto ao longo desse estudo, os cursos de formação continuada no Brasil, ainda necessitam de análises profundas acerca dos conteúdos que estão sendo trabalhados de forma frágil e aligeirada na formação dos professores desse nível de ensino. É preciso pensar que não se pode falar em práxis revolucionária no desenvolvimento infantil sem o conhecimento científico. Ir além do cotidiano em si, é tarefa essencial do professor para que sua atividade de ensino possibilite a humanização da criança.

\section{REFERÊNCIAS}

ARCE, A. O jogo e o desenvolvimento infantil na teoria da atividade e no pensamento educacional de Friedrich Froebel. Cadernos Cedes, Campinas, v 24, n. 62, p. 9-25. 2004.

CHAVES, M. Formação contínua e práticas educativas: possibilidades humanizadoras. In: CAÇÃO, M. I.; MELLO, S.A.; SILVA, V. P. da. Educação e desenvolvimento humano. Jundiaí, SP: Paco Editorial, 2014.

KLEIN, L. R. Fundamentos para uma proposta pedagógica. Disponível em: http://www.gestaoescolar.diaadia.pr.gov.br/arquivos/File/sem_pedagogica/fev_2010/funda mentos_proposta_pedagogica.pdf. Acesso em: 15 jan. 2018.

MARTINS, L. M.; MARSIGLIA, A. C. G. As perspectivas construtivistas e históricocrítica sobre o desenvolvimento da escrita. Campinas: Autores Associados, 2015. 
MELLO, S. A. Infância e humanização: algumas considerações na perspectiva HistóricoCultural. Perspectiva, Florianópolis, v. 25, n. 1, p. 83-104, jan./jun., 2007a.

MELLO, S. A. As práticas educativas e as conquistas de desenvolvimento das crianças pequenas. In: RODRIGUES, E.; ROSIN, S. M. Infância e práticas educativas. Maringá: Eduem, 2007b. p.11-22.

MELLO, S. A.; FARIAS, M. A. A escola como lugar da cultura mais elaborada. Educação (UFSM), v. 1, n. 1, p. 53-68, 2010.

OLIVEIRA, B. A prática social global como ponto de partida e de chegada da prática educativa. In: OLIVEIRA, B.; DUARTE, N. Socialização do saber escolar. 3 ed. São Paulo: Cortez: Autores Associados, 1987.

OLIVEIRA, Z. M. R.; et al. Construção da identidade docente: relatos de educadores da Educação Infantil. Cadernos de Pesquisa, v. 36, n. 129, p. 547-571, set./dez., 2006.

RAUPP, M. D.; ARCE, A. A formação de professores da Educação Infantil: algumas questões para se pensar a profissional que atuará com crianças de 0 a 3 anos.In: ARCE, A.; MARTINS, L. M. Ensinando aos pequenos de 0 a 3 anos. 2 ed. Campinas: Alínea, 2012.

SAVIANI, D. Pedagogia histórico-crítica: primeiras aproximações. 11 ed. Campinas: Autores Associados, 2013.

SILVA, J. C. O que o cotidiano das instituições de educação infantil nos revela? O espontaneísmo X o ensino. In: ARCE, A.; MARTINS, L. (Orgs). Ensinando aos pequenos de zero a três anos. 2 ed. Campinas: Alínea, 2012.

VÁZQUEZ, A. S. Filosofia da práxis. Tradução de Luiz Fernando Cardoso. São Paulo: Paz e Terra, 1968.

TORRIGLIA,P.L. A formação docente no contexto histórico-político das reformas educacionais no Brasil e na Argentina. 2004. Tese (Doutorado em Educação), Centro de Ciências da Educação. Universidade Federal de Santa Catarina, Florianópolis,2004.

\section{Como referenciar este artigo}

BARROS, Marta Silene Ferreira.; VICENTINI, Dayanne. A Epistemologia Dialética na Atividade Pedagógica: realidade e possibilidade na formação do professor da infância. Revista Ibero-Americana de Estudos em Educação, Araraquara, v. esp, n. 3, p. 19521963, dez., 2018.2 E-ISSN: 1982-5587. DOI: 10.21723/riaee.unesp.v13.iesp3.dez.2018.11123

Submetido em: 27/02/2018

Revisões requeridas: $16 / 04 / 2018$

Aprovado em: 10/06/2018 